\title{
The Relationship Between Linguistic Ability, Multilingualism, and Dementia
}

\author{
Maurits van den Noort ${ }^{\mathrm{a}, *}$, Katrien Vermeire ${ }^{\mathrm{b}}$, Heike Staudte $^{\mathrm{c}}$, Benoit Perriard ${ }^{\mathrm{d}}$, \\ Peggy Bosch ${ }^{\mathrm{c}, \mathrm{e}}$ and Sabina Lim ${ }^{\mathrm{a}}$ \\ ${ }^{a}$ Kyung Hee University, Research Group of Pain and Neuroscience, Seoul, Republic of Korea \\ ${ }^{\mathrm{b}}$ Department of Communication Sciences and Disorders, Long Island University, Brooklyn, NY, USA \\ ${ }^{\mathrm{c}}$ Psychiatric Research Group, LVR-Klinik Bedburg-Hau, Bedburg-Hau, Germany \\ ${ }^{\mathrm{d}}$ Department of Medicine, Neurology, University of Fribourg, Fribourg, Switzerland \\ ${ }^{\mathrm{e}}$ Radboud University Nijmegen, Donders Institute for Brain, Cognition and Behaviour, \\ Nijmegen, The Netherlands
}

\begin{abstract}
In a recent article of the Journal of Alzheimer's Disease, Hack et al. (2019) argue that linguistic ability rather than multilingualism is a significant predictor of dementia. In their longitudinal study, they investigated 325 religious sisters who were older than 75 years of age. Self-reports were used in order to determine multilingualism. They found that speaking two or three languages did not delay the onset of dementia. However, they did find that individuals speaking four or more languages were less likely to suffer from dementia than those speaking only one language and concluded that having linguistic ability was a more significant predictor of dementia than being multilingual. However, more research is needed in order to identify the characteristics of multilingualism most salient for the risk of dementia. In this commentary, we raise several important methodological and statistical issues that are likely to have affected the findings of Hack et al.'s study. As a result, although their study makes an important contribution to the research field, drawing a conclusion at this time that linguistic ability is more a predictor of dementia than multilingualism would be premature; moreover, their preliminary results cannot be generalized to the general population.
\end{abstract}

Keywords: Dementia, idea density, linguistic ability, longitudinal, multilingualism, risk

In a recent research article, published in this journal, Hack and colleagues [1] argue that linguistic ability rather than multilingualism is a significant predictor of dementia. In their longitudinal study, they investigated 325 religious sisters who were older than 75 years of age. They found that speaking two or three languages did not delay the onset of demen-

\footnotetext{
*Correspondence to: Maurits van den Noort, Research Group of Pain and Neuroscience, Kyung Hee University, \#1 Hoegi-Dong, Dongdaemun-gu, Seoul 130-701, Republic of Korea. Tel.: + 49 2821 7114743; E-mail: info@mauritsvandennoort.com.
}

tia. However, they did find that individuals speaking four or more languages were less likely to suffer from dementia than those speaking only one language. Moreover, they found that written linguistic ability (specifically idea density) was a more significant predictor of dementia than multilingualism. First, we want to congratulate those researchers on publishing this unique longitudinal, prospective study on the relationship between multilingualism and dementia that certainly made an important contribution to the research field. By investigating religious sisters, 
those authors were able to control for adult lifestyles, socioeconomic status, and several other important confounders [2]. Several critical methodological and statistical issues, however, need to be raised if their results are to be interpreted correctly and if further progress in the field is to be made in future studies on the relationship between multilingualism and dementia.

\section{LINGUISTIC ABILITY, SCORING, AND RELIABILITY}

In our point of view, the most fascinating result of their study is the fact that linguistic ability, which was assessed more than 40 years ago, was found to be a significant predictor of dementia. In order to investigate this, the authors analyzed autobiographical essays that were written when their participants were between 18 and 32 years of age. However, this methodology has several problems, making this fascinating result, unfortunately, unreliable. First of all, important information regarding the procedure used to rate these written autobiographical essays is missing. For instance, no information is given about who rated these written essays. Furthermore, was this rating conducted by one person or by more than one person and what was the professional background of the rater(s)? How objective was the scoring of these written autobiographical essays? For instance, why do the authors not report any intra-rater [3] or interrater reliability scores [4]? Previous research has shown that the reliability of scoring written material (regardless of the rating method used) is often low [5]. Was there a specific reason the idea density and the grammatical complexity scores were based on only the final ten sentences of each autobiography? Moreover, only 180 members out of 325 members of the original Nun Study population provided handwritten autobiographies. Furthermore, in what context were the autobiographies written and how can the authors be sure that nobody else was involved in the writing process? The study started after the autobiographies had been written, so the authors of the study could not have been present during the writing of these autobiographies. If this was conducted as an exam or school assignment, what does this say about the results? Did nervousness and/or pressure play a role in the idea density? In addition, we know that autobiographies are often unreliable [6]. Here, important information needed to interpret these linguistic ability results reliably is missing. The selection of 106 participants out of the 180 written autobiographies, the scoring procedure, and the analysis of only the last 10 sentences of the original 180 participants may have significantly affected the results of their study.

In addition, we are wondering why the researchers did not do a written re-test. That autobiographical essays written more than 40 years ago are today considered to be a reliable predictor of dementia is amazing. Had the authors included a re-test at the start of the longitudinal study, they would have had data for all participants and there would have been an opportunity to compare the first essay ratings of the healthy participants with those of the second essay ratings of the healthy older adults and the patients with dementia, which is a reliable method for determining the relationship between written linguistic ability and dementia. Moreover, how do the researchers explain this finding? The authors give no explanation why this relationship between autobiographical essays written more than 4 decades ago and the onset of dementia would exist.

Furthermore, that the researchers only investigated the written linguistic domain in order to determine linguistic ability is important to note [1]. What about the verbal domain, the auditory domain, etc.? In our opinion, drawing any firm conclusions at this time about linguistic ability as a predictor of dementia based on these preliminary written data would be premature.

\section{GENDER DIFFERENCES}

The authors correctly state that the unique nature of their participants (religious sisters) may have produced results that were less generalizable to the general public. However, they are mistaken when they write "there is no cause to believe, however, that the relationship of multilingualism with dementia etiology would be altered in our population." The authors seem to forget that they only investigated women. Gender differences may exist in the cognitive protective effect of lifelong bilingualism, as previous research discovered gender differences in healthy elderly individuals and in patients with Alzheimer's disease (AD) [7]. In a neuroimaging study on 282 patients with AD, a posterior temporoparietal association in men and a frontal and limbic association in women were discovered, and men and women were found to differ with respect to the involvement of different brain networks [7]. Moreover, previous research revealed that gender 
differences existed in foreign language learning as female learners were found to outperform male learners in foreign language writing and speaking [8]. Furthermore, previous research revealed the existence of gender differences in the neural processes of cognitive control $[9,10]$ and in the prevalence of dementia (including AD) [11]. Therefore, future research should take gender differences better into account $[12,13]$ and directly investigate such gender differences in the cognitive reserve-enhancing effect of multilingualism by using behavioral and neuroimaging measurements, particularly if one wants to use foreign language learning as a kind of treatment method in enhancing cognitive reserve in the aged and in delaying the onset and/or progress of dementia $[1,2]$.

\section{MISSING SUBJECTIVE AND OBJECTIVE DATA}

The authors are correct when they state that the determination of multilingualism based on selfreports is a limitation of their study [1]. There are mixed results regarding the reliability and validity of self-reports. Some studies have found that selfestimated language skills are reliable and valid [14, 15], while in other research, self-reports were found to suffer from a low reliability and validity [16]. In the Hack et al. [1] study, no "objective" data about important mediating variables, such as foreign language proficiency, foreign language use, language switching, etc., are available. Moreover, why did the authors not provide any subjective (self-report) data on the above-mentioned variables? Language background questionnaires, like the Language Experience and Proficiency Questionnaire (LEAP-Q) [15], are able to provide important information about the individual's multilingual language status with predictable relationships between self-reported and behavioral measures. Lifelong multilingualism is a complex individual process, and many factors seem to influence it and might affect the extent of the cognitive reserve-enhancing effect of lifelong multilingualism [2].

\section{LANGUAGE FAMILY MIGHT MATTER}

Moreover, unfortunately, no information is given on the kinds of languages the religious sisters spoke. That is a real pity because the language family [17], whether the languages are related or not (e.g., Span- ish, French, Italian, and Portuguese belong to the same language group: The Romance language family), might matter in the degree of the cognitive reserve-enhancing effect of lifelong multilingualism [12] because more or fewer suppression (cognitive control) skills are required.

\section{SMALL SAMPLE SIZE OF MULTILINGUALS}

Finally, another limitation of the Hack et al. [1] study is the small number of multilinguals in their sensitivity analyses (e.g., 28 individuals who speak more than three languages and only five individuals who speak more than four languages). The lack of statistical power [18] may have also affected the findings of their sensitivity analysis.

\section{CONCLUSION}

When all of the above are considered, despite the fact that the study by Hack et al. [1] is an important contribution to the research field, drawing a conclusion at this time that linguistic ability is more a predictor of dementia than multilingualism would be premature. Moreover, the preliminary results of their study on a subgroup of (highly educated) religious sisters cannot be generalized to the general male and female population.

\section{DISCLOSURE STATEMENT}

Authors' disclosures available online (https:// www.j-alz.com/manuscript-disclosures/19-0807r1).

\section{REFERENCES}

[1] Hack EE, Dubin JA, Fernandes MA, Costa SM, Tyas SL (2019) Multilingualism and dementia risk: Longitudinal analysis of the Nun study. J Alzheimers Dis 71, 201-212.

[2] van den Noort M, Vermeire K, Bosch P, Staudte H, Krajenbrink T, Jaswetz L, Struys E, Yeo S, Barisch P, Perriard B, Lee SH, Lim S (2019) A systematic review on the possible relationship between bilingualism, cognitive decline, and the onset of dementia. Behav Sci 9, 81.

[3] Cohen Y (2017) Estimating the intra-rater reliability of essay raters. Front Educ 2, 49.

[4] Kaiser RA, Davis TM, Litowitz D, Argall R (1992) Interrater reliability of a holistically scored essay test used for student placement in remedial/developmental writing classes. J Coll Read Learn 24, 17-26.

[5] Kayapinar U (2014) Measuring essay assessment: Intrarater and inter-rater reliability. Eurasian J Educ Res 57, 113-136. 
[6] Shen D, Xu D (2007) Intratextuality, intertextuality, and extratexuality: Unreliability in autobiography versus fiction. Poetics Today 28, 43-88.

[7] Malpetti M, Ballarini T, Presotto L, Garibotto V, Tettamanti M, Perani D, Alzheimer's Disease Neuroimaging Initiative (ADNI) database, Network for Efficiency and Standardization of Dementia Diagnosis (NEST-DD) database (2017) Gender differences in healthy aging and Alzheimer's dementia: A ${ }^{18}$ F-FDG-PET study of brain and cognitive reserve. Hum Brain Mapp 38, 4212-4227.

[8] van der Slik FW, van Hout RW, Schepens JJ (2015) The gender gap in second language acquisition: Gender differences in the acquisition of Dutch among immigrants from 88 countries with 49 mother tongues. PLoS One 10, e0142056.

[9] Li CR, Zhang S, Duann JR, Yan P, Sinha R, Mazure CM (2009) Gender differences in cognitive control: An extended investigation of the Stop-Signal task. Brain Imaging Behav 3, 262-276.

[10] Huster RJ, Westerhausen R, Herrmann CS (2011) Sex differences in cognitive control are associated with midcingulate and callosal morphology. Brain Struct Funct 215, 225-235.

[11] Rocca WA (2017) Time, sex, gender, history, and dementia. Alzheimer Dis Assoc Disord 31, 76-79.
[12] van den Noort M, Struys E, Bosch P, Jaswetz L, Perriard B, Yeo S, Barisch P, Vermeire K, Lee SH, Lim S (2019) Does the bilingual advantage in cognitive control exist and if so, what are its modulating factors? A systematic review. Behav Sci 9, 27.

[13] Antoniou M, Wright SM (2017) Uncovering the mechanisms responsible for why language learning may promote healthy cognitive aging. Front Psychol 8, 2217.

[14] Li P, Sepanski S, Zhao X (2006) Language history questionnaire: A web-based interface for bilingual research. Behav Res Methods 38, 202-210.

[15] Marian V, Blumenfeld HK, Kaushanskaya M (2007) The language experience and proficiency questionnaire (LEAP-Q): Assessing language profiles in bilinguals and multilinguals. J Speech Lang Hear Res 50, 940-967.

[16] Ayers JW (2010) Measuring English proficiency and language preference: Are self-reports valid? Am J Public Health 100, 1364-1366.

[17] Rama T (2013) Phonotactic diversity predicts the time depth of the world's language families. PLoS One 8, e63238.

[18] Bakker M (2015) Power problems: $N>138$. Cortex 73, 367368. 